\title{
Efeitos territoriais de políticas educacionais: a recente expansão e interiorização do ensino federal em cidades não metropolitanas no Ceará
}

Spatial effects of educational policies: recent expansion and internalization of federal education in non-metropolitan cities in Ceará

Rérisson Máximo[a,b] (1)

[a] Universidade de São Paulo (USP), Faculdade de Arquitetura e Urbanismo, São Paulo, SP, Brasil

[b] Instituto Federal do Ceará (IFCE), Quixadá, CE, Brasil

Como citar: Máximo, R. (2020). Efeitos territoriais de políticas educacionais: a recente expansão e interiorização do ensino federal em cidades não-metropolitanas no Ceará. urbe. Revista Brasileira de Gestão Urbana, 12, e20190080. https://doi.org/10.1590/2175-3369.012.e20190080

\section{Resumo}

A recente expansão do ensino federal superior e técnico que caracteriza as políticas educacionais em nível nacional a partir da virada do século XXI se fundamenta em um duplo processo de democratização e interiorização. Ao mesmo tempo que possibilitou ao setor público recuperar certo protagonismo no atendimento da demanda por aquelas modalidades de ensino, essa expansão representou impactos significativos, principalmente, para municípios de pequeno e médio portes, na medida em que os complexos educacionais implantados interferiram na dinâmica e na estrutura intraurbana dessas cidades. 0 texto apresenta e discute, a partir da realidade cearense, aspectos sobre a dimensão territorial do processo de expansão do ensino federal para cidades não metropolitanas, bem como argumenta que a implantação de novos campi está associada à flexibilização da legislação urbanística, ao aumento da demanda por mobilidade urbana, à dinamização do mercado imobiliário e ao incremento do comércio e dos serviços.

Palavras-chave: Universidades federais. Institutos federais. Educação. Cidades. Impactos urbanos.

\section{Abstract}

The recent process of higher and technical education's expansion, which characterizes federal educational policies from the turn of the 21st century, is based on a double process of democratization and internalization. At the same time that this expansion has enabled the Brazilian State to recover some of its leading role in meeting the demand for those educational levels, it impacted mainly small and medium sized municipalities, as the educational complexes implanted changed intraurban dynamics and structure of those cities. This paper presents and discusses some aspects of territorial dimension regarding expansion of federal education in non-metropolitan cities from Ceará, and argues that the implementation of new campuses is associated with the flexibilization of urban legislation, the increase of urban mobility demand, the dynamization of the real estate market and the increase in trade and services.

Keywords: Federal universities. Federal institutes. Education. Cities. Urban impacts.

RM é arquiteto e urbanista, mestre e doutorando em Arquitetura e Urbanismo, e-mail: maximo@usp.br 


\section{Introdução}

A recente expansão do ensino federal superior e técnico que caracteriza as políticas educacionais em nível nacional a partir da virada do século XXI se fundamenta em um duplo processo de democratização e de interiorização. Ao mesmo tempo que o ingresso e a permanência em universidades e institutos federais se tornaram cada vez mais democráticos com a ampliação de vagas, a implementação de cotas sociais e raciais e o fortalecimento das ações de assistência estudantil, também se observou a interiorização daquelas modalidades de ensino, a partir da instalação de novos campi universitários, sobretudo em cidades não metropolitanas de pequeno e médio portes. Dois marcos importantes desse processo são a implementação do Programa de Apoio a Planos de Reestruturação e Expansão das Universidades Federais e a constituição da Rede Federal de Educação Profissional, Científica e Tecnológica, que permitiram a expansão e a interiorização de universidades e de institutos federais.

Tal processo possibilitou ao setor público recuperar certo protagonismo no atendimento da demanda por aquelas modalidades de ensino no Brasil, ainda que o ensino superior privado tenha tido um incremento mais significativo ${ }^{1}$. Ao mesmo tempo, representou impactos territoriais significativos nas cidades, principalmente para aquelas não metropolitanas, na medida em que tais empreendimentos estão associados a mudanças na dinâmica e na estrutura intraurbana daquelas cidades. Por causa da instalação desses novos complexos educacionais dos mais diversos portes, localizados, principalmente, em municípios pequenos e médios, há o aumento da demanda por mobilidade urbana, em razão do necessário deslocamento para os campi, em regra, localizados em áreas distantes da malha urbana adensada; o incremento do mercado imobiliário local, com a construção de novas edificações voltadas para a locação, sobretudo para os estudantes; o aumento do comércio e dos serviços locais com atividades voltadas a esse novo público; e ainda a flexibilização da legislação urbanística, com a ampliação do perímetro urbano e a inclusão desses novos campi em áreas anteriormente consideradas rurais, ação que contribui, inclusive, para a implantação de novos loteamentos e condomínios residenciais.

Diante dessa conjuntura, o texto apresenta e discute aspectos sobre a dimensão territorial do processo de expansão do ensino federal em municípios cearenses não metropolitanos e argumenta que a implantação desses novos campi está associada, para além de um maior dinamismo econômico, a impactos na dinâmica e na estrutura intraurbana dessas cidades. Como recursos metodológicos, recorreu-se a trabalhos sobre o processo de expansão do ensino federal, documentos oficiais e trabalhos de campo. Como estudos de caso, adotaram-se os municípios cearenses não metropolitanos de Quixadá e Crateús, por possuírem porte populacional característico daqueles que passaram a abrigar novos campi universitários e ainda por serem os únicos no Ceará que contam duplamente com um novo campus de uma universidade federal e um novo campus de um instituto federal, condição que permite uma certa aproximação entre a realidade dessas duas cidades, ao mesmo tempo que as tornam emblemáticas no processo que se pretende discutir.

0 texto está dividido em quatro seções, além desta introdução. Na primeira, intitulada "Rumo ao interior: a expansão do ensino federal", são apresentados alguns aspectos gerais que situam e caracterizam o processo recente de expansão do ensino federal, sobretudo por meio de novos campi de universidades federais (UFs) e de institutos federais (IFs) implantados em cidades não metropolitanas. Chamada "Expansão do ensino federal no Ceará", a segunda seção busca um recorte territorial mais específico, sendo mostrados aspectos sobre o processo de implantação de novos campi universitários no território cearense, principalmente nas cidades não metropolitanas. "A dimensão territorial da expansão

\footnotetext{
10 ensino superior privado no Brasil também passou por intenso processo de expansão quantitativamente bastante superior ao apresentado pelo ensino federal. Se, em 1997, existiam 689 instituições particulares de ensino superior no Brasil, esse número chegou a 2.111 no ano de 2016, segundo dados das Sinopses Estatísticas da Educação Superior do Instituto Nacional de Estudos e Pesquisas Educacionais Anísio Teixeira (Inep). Neste texto, será abordada apenas a expansão do ensino federal, opção explicada por dois aspectos: primeiro, pelo fato de a expansão do ensino federal ter ocorrido sobretudo em municípios não metropolitanos, reforçando o processo de interiorização, conforme indicado para a realidade cearense; segundo, pelo escopo pretendido de relacionar políticas educacionais e urbanas, atribuições diretamente associadas ao Estado. Sobre a expansão do ensino superior privado, ver Pereira \& Brito (2018) e Canziani et al. (2018).
} 
educacional" constitui a terceira seção do artigo, em que são discutidos, de maneira mais aproximada, alguns dos impactos que a implantação e o funcionamento desses novos campi causam na estrutura e na dinâmica intraurbana de cidades, a partir dos estudos de caso em Quixadá e Crateús. Por fim, são apresentadas "Algumas notas finais" sobre os efeitos territoriais de políticas educacionais pela recente expansão e interiorização do ensino federal.

\section{Rumo ao interior: a expansão do ensino federal}

Historicamente, o acesso às instituições federais de ensino ocorreu de forma bastante restrita, com recortes territoriais e de renda. Segundo Corbucci $(2014$, p. 7), isso poderia ser explicado "[...] pela implantação tardia de cursos superiores no país, mas também pela natureza e abrangência das políticas e ações voltadas à reversão ou mitigação desta situação". Os dados censitários ajudam a reforçar esse argumento. Em 2000, segundo dados do censo demográfico do IBGE (2000), apenas 6,8\% da população brasileira com idade igual ou superior a 25 anos possuía ensino superior. Dados publicados pela Organização para a Cooperação e Desenvolvimento Econômico (OCDE) referentes ao ano de 2009 apontam que apenas 11 de cada 100 brasileiros entre 25 e 64 anos possuíam ensino superior completo, ao passo que, nos países-membros daquela organização, esse número seria, em média, de 31\% (OCDE, 2012). Dados de 2010 indicam que apenas 12\% dos brasileiros com idade entre 25 e 64 anos completaram algum tipo de educação superior (IBGE, 2010). Tais dados, ao mesmo tempo que mostram uma recente curva ascendente do percentual de brasileiros com diploma universitário, também revelam sua reduzida ordem de grandeza quando comparado com o universo da população nacional. Cenário semelhante, predominantemente restritivo, ocorre com o acesso ao ensino técnico e tecnológico.

Ademais, estudos também apontam que melhores condições socioeconômicas, em particular a renda, são um fator de alta correlação com o acesso ao ensino superior. Segundo a Associação Nacional dos Dirigentes das Instituições Federais de Ensino Superior no Brasil (Andifes), 41\% dos alunos vinham de famílias com renda bruta inferior a três salários mínimos (Andifes, 2011), números maiores nas regiões Nordeste e Norte por causa das grandes disparidades regionais. Comparando tais valores com os dados do censo demográfico de 2010 (IBGE, 2010), que apontam um percentual de 56\% de famílias com renda inferior a três salários mínimos, observa-se leve superioridade do indicador renda bruta familiar dos estudantes universitários em relação ao universo populacional brasileiro, apesar dos avanços (ou mesmo por conta deles) já observados ao final da primeira década do século XXI.

Para além dos aspectos socioeconômicos, o acesso restrito ao ensino federal também tem uma dimensão territorial. Historicamente, houve uma concentração regional de universidades e escolas técnicas federais implantadas, sobretudo, em capitais, regiões metropolitanas e grandes centros regionais, geralmente aqueles lugares com maior dinamismo econômico ${ }^{2}$, pelo menos até o começo do século XXI. Antes de 2003, existiam 140 campi de escolas técnicas federais e 148 campi de universidades federais, localizados em apenas 184 dos mais de 5.507 municípios existentes naquele momento ${ }^{3}$. No caso da população interiorana, isso contribuiu para elevar o caráter restritivo do acesso à formação superior e à qualificação profissional para as camadas sociais de maior renda daqueles municípios, grupo que conforma uma elite possuidora de maiores condições para se deslocarem para outras cidades onde os campi de universidades e escolas técnicas federais foram majoritariamente implantados até então.

Contudo, esse quadro sofreu alterações significativas diante de políticas públicas no setor educacional implantadas a partir da primeira década deste século pelo governo federal. Ocorreram mudanças importantes, principalmente, no âmbito da educação superior e no ensino técnico e tecnológico. Tais mudanças estão associadas aos já referidos processos de democratização e interiorização que

\footnotetext{
2 Até 2003, os campi de universidades federais haviam sido implantados, em sua maioria, em capitais, regiões metropolitanas e centros regionais. Já os campi de escolas técnicas federais estavam presentes em uma maior diversidade de categorias de cidades, inclusive em municípios de pequeno e médio portes, como ocorreu com as escolas agrotécnicas.

${ }^{3}$ Dados obtidos no Sistema Integrado de Monitoramento, Execução e Controle do MEC.
} 
caracterizam a recente expansão do ensino federal. A partir de meados da primeira década do século XXI, já no governo Lula, implantaram-se políticas e programas que, quando comparados às ações de reestruturação da educação empreendida no governo anterior, ora tenderam à continuidade, como o Programa Universidade para Todos (ProUni), de 2005, e o Fundo de Financiamento Estudantil (Fies), de 2010, ora tenderam a inovações. Entre estas se destacam, em sequência temporal, a Universidade Aberta do Brasil (UAB), de 2006; a Rede Federal de Educação Profissional, Científica e Tecnológica (RFEPCT), de 2007; o Programa de Apoio a Planos de Reestruturação e Expansão das Universidades Federais (Reuni), de 2007, que foi subsidiado pelo Plano Nacional de Assistência Estudantil (Pnaes), no mesmo ano, e, pelo Sistema de Seleção Unificada (Sisu), de 2010; e ainda o Programa Nacional de Acesso ao Ensino Técnico e Emprego (Pronatec), de 2011. Para o escopo pretendido para este artigo, serão abordadas, especificamente, a constituição da RFEPCT e a implementação do Reuni.

\section{Expansão do ensino superior federal}

Instituído pelo Decreto Federal no 6.096/2007, o Programa de Apoio a Planos de Reestruturação e Expansão das Universidades Federais (Reuni) é o principal marco do movimento recente de expansão da educação superior federal no Brasil. Com o objetivo de ampliar e interiorizar as universidades públicas federais e também atender aos objetivos do Plano Nacional de Educação (PNE) para o decênio 2001-2010 (Brasil, 2001), essa política pública foi uma das principais ações voltadas para o ensino superior no período. Sua implantação foi cercada por duas grandes discussões, de certa forma polarizadas: primeiro, ocasionaria a precarização do trabalho docente e a mercantilização do ensino; e, segundo, proporcionaria a interiorização e a democratização do acesso e levaria o setor público a recuperar o protagonismo no atendimento da demanda por ensino superior no Brasil (Mota, 2016). Consistiu em uma série de investimentos destinados à expansão do acesso ao ensino superior gratuito, ao ingresso de estudantes de camadas populares, ao combate à evasão, à ocupação de vagas ociosas, à criação de cursos noturnos e à interiorização do ensino superior federal pelo país (Brasil, 2007a; Lima, 2011).

Esse recente processo de expansão das universidades federais - cujo marco inicial é a criação do Reuni em 2007, que prosseguiu até 2012, mas ainda apresenta ações pontuais que se estendem até a atualidade - pode ser classificado em três ciclos: reestruturação, interiorização, e integração e internacionalização (Brasil, 2014). 0 ciclo de reestruturação se caracteriza pela expansão a partir das universidades e campi existentes, com a ampliação de vagas associadas ao incremento da infraestrutura e do quantitativo de docentes. A interiorização decorre quando se inicia a implantação dos novos complexos educacionais, vinculados às universidades existentes ou implantados a partir de novas universidades criadas, que também passaram a contar com alguns campi existentes, mas que foram desmembrados de outras universidades. Nesse mesmo processo, ocorre a integração e a internacionalização, com a implantação de universidades multicampi, alguns inclusive em diferentes Estados, com propostas acadêmicas voltadas à integração regional ou internacional (Brasil, 2014). Na prática, é o somatório desses dois últimos ciclos que caracteriza o que se tem tratado neste texto como interiorização, especificamente no que se refere às universidades federais.

O número de cursos superiores em universidades federais, que vinha apresentando tímido aumento até o começo dos anos 2000, ganhou um salto significativo a partir de 2007, indo de 2.450 cursos de graduação em 2004 para 5.879 em 2014. Esse aumento de quase 140\% em menos de uma década significou, consequentemente, o aumento do número de vagas. Se, em 2008, havia 643.101 estudantes matriculados, em 2014 esse número já somava 1.083.586, um crescimento de quase $70 \%$ da população universitária federal em apenas seis anos (Brasil, 2012, 2014). Essa expansão proporcionou um aumento significativo das matrículas em universidades federais, distanciando-se do tradicional modelo de oferta de vagas em capitais, regiões metropolitanas e grandes centros regionais ${ }^{4}$. De 2003 a 2014, houve um

\footnotetext{
${ }^{4}$ Dados coletados nos campi da UFC nas cidades cearenses de Crateús e Quixadá indicam, inclusive, que há uma inversão no movimento interior-capital por parte dos estudantes do ensino superior federal.
} 
salto de 45 para 63 universidades federais, e essa expansão trouxe também um expressivo crescimento na quantidade de campi no interior do país. Em 2003, existiam 148 campi de universidades federais, ao passo que, em 2014, esse número passou para 3215 . 0 resultado dessa interiorização do ensino superior federal foi a elevação acentuada do número de municípios diretamente atendidos por universidades federais, a partir da construção dos novos campi e da oferta de cursos de graduação e demais serviços acadêmicos universitários. Se, em 2003, apenas 114 municípios possuíam campus universitário, esse número se elevou, em 2014, para 289 municípios $^{6}$.

\section{Expansão da educação profissional, científica e tecnológica}

Concomitante ao ciclo de expansão do ensino superior federal, tem-se a expansão do ensino técnico e tecnológico por meio dos institutos federais. Esse processo está inserido em um contexto mais amplo de reestruturação da rede de educação profissional, iniciado com o Decreto Federal no 6.095/2007, que buscava alterar a conformação daquela rede de maneira a instituir uma nova arquitetura organizacional. É esse o marco legal que estabeleceu as diretrizes para o processo de integração das diversas instituições federais de educação tecnológica para sua transformação em institutos federais (Brasil, 2007b).

Em 2008, por meio da Lei Federal no 11.892, foi instituída a Rede Federal de Educação Profissional, Científica e Tecnológica (RFEPCT) e foram criados os Institutos Federais de Educação, Ciência e Tecnologia, ou apenas Institutos Federais (IFs), reunindo escolas técnicas federais, escolas agrotécnicas federais, escolas técnicas vinculadas a universidades federais e centros federais de educação tecnológica. Conforme aquela legislação, os IFs seriam instituições com estrutura diferenciada, verticalizada, de educação superior, básica e profissional, pluricurriculares e multicampi, especializados na oferta de educação profissional e tecnológica nas diferentes modalidades de ensino, com base na conjugação de conhecimentos técnicos e tecnológicos com as suas práticas pedagógicas (Brasil, 2008).

O novo modelo institucional apresenta-se como uma política pública comprometida com "[...] $o$ desenvolvimento científico e tecnológico associado ao desenvolvimento econômico, político e social numa perspectiva progressista" (Pacheco, 2010, p. 17). Para Pacheco (2010, p. 14), o papel que está previsto para os IFs é o de "[...] garantir a perenidade das ações que visem incorporar, antes de tudo, setores sociais que historicamente foram alijados dos processos de desenvolvimento e modernização do Brasil". 0 processo de expansão da educação profissional cumpriu papel importante na ampliação do acesso à escolarização em nível profissionalizante, mas também no ensino técnico e tecnológico. Para além, os IFs também contribuíram para a expansão do ensino superior, tanto de bacharelados quanto de licenciaturas, seguindo a obrigatoriedade imposta pelos documentos institucionais que regulamentam o funcionamento dos Institutos.

Inicialmente, foram criados 38 IFs a partir da adesão de 75 instituições, dentre todas as 102 que poderiam optar, em um processo que aglutinou campi e instituições em determinados IFs ${ }^{7}$. Esses institutos foram compostos de todas as 36 escolas agrotécnicas federais, de 31 dos 33 centros federais de educação tecnológica em funcionamento e de 8 das 32 escolas técnicas vinculadas às universidades federais. Além dessas unidades, a RFEPCT é formada ainda por instituições federais que não aderiram ao formato de IFs, mas que também oferecem educação profissional em diferentes níveis. São 2 centros federais de educação tecnológica, 25 escolas técnicas vinculadas às universidades federais, o Colégio Pedro II e 1 universidade tecnológica federal (Brasil, 2009).

No processo de constituição daquela rede, foi elaborado o plano de expansão da RFEPCT, que foi dividido em três fases temporalmente sequenciais: Fase 1 (2005-2007), Fase 2 (2007-2010) e Fase 3 (2011-2104), esta última com ações pontuais que ainda ocorrem na atualidade. Na primeira fase, foi

\footnotetext{
5 Dados obtidos no Sistema Integrado de Monitoramento, Execução e Controle do MEC.

${ }^{6}$ Dados sobre cursos e matrículas obtidos de INEP (2014a, 2014b) e dados sobre campi, universidades e municípios obtidos no Sistema Integrado de Monitoramento, Execução e Controle do MEC.

${ }^{7}$ Como ocorreu com o IFCE, que incorporou dois campi de escolas agrotécnicas das cidades de Cedro e Iguatu.
} 
anunciada a construção de 64 campi dos IFs. 0 governo federal tinha como propósito implantar as chamadas escolas técnicas nos Estados ainda desprovidos dessas instituições, além de outras unidades que seriam localizadas, de preferência, em periferias de grandes centros urbanos e em municípios interioranos, distantes das capitais e dos centros urbanos mais ricos (Brasil, 2008). Pode-se observar que esses critérios estavam diretamente ligados às estratégias de desenvolvimento territorial.

Tendo como slogan "Uma escola técnica em cada cidade-polo do país", a segunda fase da expansão da RFEPCT previa a instalação de 150 novas unidades de ensino que atingiriam o total de 214. Conforme dados da Secretaria de Educação Profissional e Tecnológica (SETEC) do MEC, a definição dessas cidades-polo que receberiam um campus de IFs se daria a partir de critérios objetivos, tais como: distribuição territorial equilibrada das novas unidades, cobertura do maior número possível de mesorregiões, sintonia com os arranjos produtivos locais e aproveitamento de infraestruturas físicas existentes. Nesse momento, foram contabilizadas 214 novas unidades de ensino, que, somadas às 140 escolas técnicas já existentes, atingiriam o número de 354 (Brasil, 2011). Em 2011, foi anunciada a terceira fase, sendo projetada, para esse primeiro ano, a implantação de 86 novos campi de IFs, dos quais 46 eram remanescentes da Fase 2. Havia ainda a previsão de implantação de 60 novas unidades de ensino a cada ano, durante a vigência do Plano Nacional de Educação que estava em elaboração ${ }^{8}$, o que levaria a RFEPCT à configuração de 1.000 unidades até o final da atual década (Brasil, 2011).

Um aspecto importante e inovador foi a utilização de parâmetros técnicos em detrimento de critérios políticos para a definição dos municípios onde seriam instaladas as novas unidades, em movimento contrário ao que geralmente tem sido observado na implementação de políticas públicas territorializáveis (Pacheco et al., 2010). Por se pautar em objetivos bem definidos, como a elevação da oferta de matrículas, a interiorização da rede e a implantação de instituições em locais antes não beneficiados, essa expansão demandou metodologia que pudesse contribuir para identificar as mesorregiões e as cidades-polo que receberiam novos campi. Para tanto, foram utilizados estudos e dados estatísticos de instituições importantes, como IBGE, Instituto de Pesquisa Econômica Aplicada (Ipea) e Instituto Nacional de Estudos e Pesquisas Educacionais Anísio Teixeira (Inep).

0 resultado foi a tendência à interiorização dos IFs. De acordo com um relatório de abrangência nacional de um dos principais órgãos de controle da administração pública (TCU, 2012), até 2012 cerca de $85 \%$ dos campi dos IFs estavam localizados fora das capitais. Outro dado que reforça essa constatação é que, dos mais de 300 campi existentes naquele ano, 176 estavam localizados em municípios com menos de 50 mil habitantes, e destes, 45 em municípios com população inferior a 20 mil moradores. Aquele relatório do TCU considera que a expansão da RFEPCT teve duas direções principais: ampliação do número de vagas e infraestrutura das escolas preexistentes com a construção de novos campi nas regiões metropolitanas, mas também a interiorização dos IFs, visando ocupar os lugares de maior carência socioeconômica (TCU, 2012, p. 8).

\section{A expansão do ensino federal no Ceará}

No Estado do Ceará, é possível observar a materialização do processo de expansão das instituições federais de ensino descrito anteriormente. Se, até o começo do século XXI, o ensino federal estava presente em apenas sete municípios do Estado, essa realidade se alterou consideravelmente nos anos seguintes, com um incremento significativo no número de complexos educacionais espalhados pelo interior do Estado. Antes do recente processo de expansão, o ensino federal em território cearense era oferecido em cinco campi da Universidade Federal do Ceará - dos quais três estavam localizados na

\footnotetext{
${ }^{8} 0$ novo Plano Nacional de Educação referente ao decênio 2011-2020, previsto para ser aprovado em 2011 e que substituiria o anterior, começou a vigorar apenas em 2014.
} 
capital -, três campi da então Escola Técnica Federal do Ceará (que depois se tornou CEFET-CE e, atualmente, IFCE) e dois campi de escolas agrotécnicas federais ${ }^{9}$.

A partir de 2007, quando foi iniciada a implantação de novos complexos educacionais de universidades e institutos federais pelo país, foram construídos 39 novos campi em 34 municípios cearenses, dos quais 31 passaram a contar pela primeira vez com um complexo educacional de ensino federal. Desse total de novos campi, 22 ficavam em municípios com mais de 50 mil habitantes, dos quais 16 foram implantados em municípios não metropolitanos, recorte territorial das análises aqui realizadas.

Quadro 1 - Municípios cearenses não metropolitanos com população superior a 50 mil habitantes em 2010

\begin{tabular}{ccccc}
\hline Município & População (2018) & População (2010) & Campus IF & Campus UF \\
\hline Acaraú & 62557 & 57340 & sim & - \\
Acopiara & 53931 & 51117 & sim & - \\
Aracati & 74084 & 68881 & sim & - \\
Boa Viagem & 54440 & 52263 & sim & - \\
Camocim & 63408 & 60025 & sim & - \\
Canindé & 78049 & 74308 & sim & sim \\
Crateús & 74982 & 72687 & sim & - \\
Granja & 54729 & 52572 & - & sim \\
Icó & 67972 & 65405 & - & - \\
Iguatu & 103255 & 96432 & sim & - \\
Itapipoca & 128135 & 115637 & sim & - \\
Limoeiro do Norte & 59278 & 56166 & sim & sim \\
Morada Nova & 62069 & 61941 & sim & - \\
Quixadá & 87116 & 80270 & - & sim \\
Quixeramobim & 79081 & 71500 & - & - \\
Russas & 76884 & 69592 & sim & - \\
Tauá & 58517 & 55631 & sim & - \\
Tianguá & 75140 & 68688 & - & - \\
Trairi & 55535 & 51233 & sim & \\
\hline
\end{tabular}

Fonte: Elaborado a partir de dados do Censo Demográfico (BGE, 2010), da Estimativa Populacional de 2018 publicada pelo Instituto Brasileiro de Geografia e Estatistica (IBGE) e do Sistema Integrado de Monitoramento Execução e Controle (Simec) do Ministério da Educação (MEC).

Os municípios cearenses não metropolitanos com população superior a 50 mil habitantes em 2000, com a indicação da presença de campus de instituição federal de ensino, podem ser vistos no Quadro 1. Do total de 21 municípios naquelas condições, apenas três não possuíam um campus de instituto ou universidade federal. Além disso, dois deles apresentavam simultaneamente um campus de cada uma dessas instituições: Crateús e Quixadá, exatamente os municípios escolhidos como estudo de caso para as análises que serão realizadas adiante. Atualmente, o ensino federal está presente em 38 cidades, o que representa $1 / 5$ dos municípios cearenses, com um total de 49 campi das quatro instituições federais de ensino presentes no Estado: a Universidade Federal do Ceará (UFC), a Universidade Federal do Cariri (UFCA), a Universidade Federal da Integração Internacional da Lusofonia Afro-Brasileira (Unilab) e o Instituto Federal do Ceará (IFCE).

\footnotetext{
${ }^{9}$ Além da capital Fortaleza, que contava com três campi da UFC e um do então CEFET-CE, o ensino federal estava presente nas cidades de Cedro e de Juazeiro do Norte, com unidades descentralizadas do CEFET-CE; de Iguatu e de Crato, com escolas agrotécnicas; e de Sobral e de Barbalha, com campi da UFC.
} 

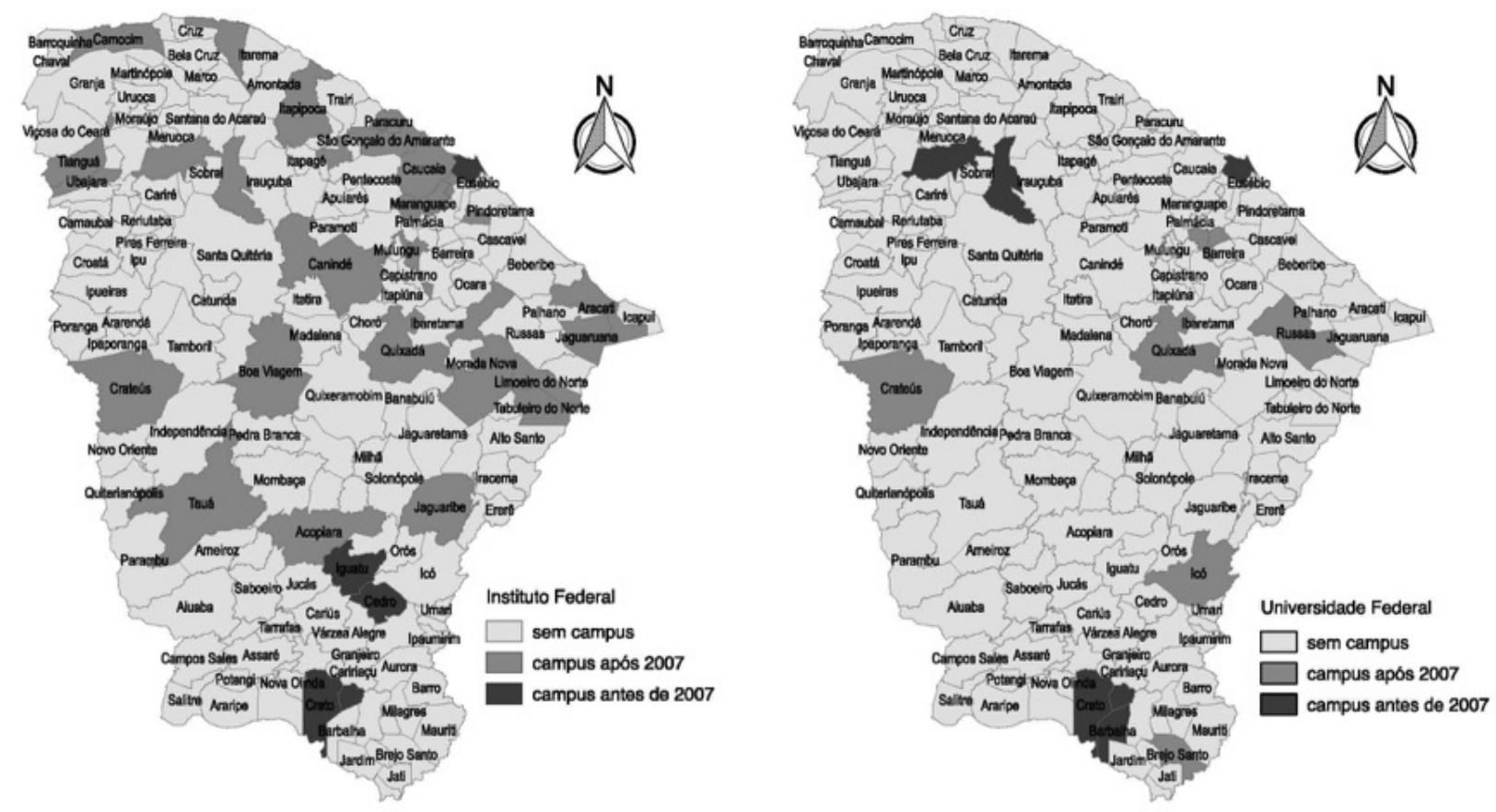

Figura 1 - Localização dos campi do instituto e das universidades federais no Ceará, por período de implantação. Fonte: Elaborado a partir de base cartográfica do IBGE (2010) e dados do Sistema Integrado de Monitoramento Execução e Controle (Simec) do Ministério da Educação (MEC)

\section{Ensino superior e as universidades federais}

A Universidade Federal do Ceará (UFC) foi a primeira universidade do Estado, criada apenas em 1957, embora já houvesse outras instituições de ensino superior desde meados do século XIX, mas concentradas na capital. Foi também na década de 1950 que teve início um pontual processo de interiorização do ensino superior, com cursos ofertados por instituições católicas em Crato e, posteriormente, nos anos 1960, em Sobral e, na década de 1970, em Limoeiro do Norte (Santos, 2015). Tais instituições depois foram transformadas em universidades estaduais, demonstrando o papel que o governo local assumiu na interiorização do ensino superior. Foi a partir desse processo que surgiram a Universidade Estadual do Ceará (UECE) - com sede em Fortaleza, mas com outras unidades em alguns municípios do interior -, a Universidade Estadual Vale do Acaraú (UVA) e a Universidade Regional do Cariri (URCA).

A interiorização efetiva via governo federal só se iniciou na década de 2000. Antes mesmo do Reuni, a UFC - então única universidade federal no território cearense - começou um processo de interiorização com a implantação dos campi de Sobral e Barbalha, em 2001. Em 2008, já como reflexo do processo de expansão decorrente do Reuni, foi criado o campus de Juazeiro do Norte e foram iniciadas as obras do campus de Crato. As três cidades passariam a compor o campus Cariri da UFC. Em 2010, foi inaugurado o campus de Quixadá da UFC, em um segundo movimento de expansão, já pelo Reuni, da maior universidade federal do Estado. Também em 2010, a partir da Lei Federal no 12.289 , foi criada a Universidade da Integração Internacional da Lusofonia Afro-Brasileira (Unilab), com sede em Redenção, mas com outros campi em Acarape, cidade vizinha, e São Francisco do Conde, na Bahia.

Em 2013, por meio da Lei Federal no 12.826, foi criada a Universidade Federal do Cariri (UFCA), por desmembramento do campus Cariri da UFC que aglutinava unidades em Juazeiro do Norte, Barbalha e Crato. Estes passaram a integrar a UFCA, além de terem sido criados ainda os campi de Icó e de Brejo Santo. Em 2014, foram implantados mais dois campi da UFC no interior: um na cidade de Russas e outro na cidade de Crateús. Atualmente, está em construção outro campus da UFC em Itapajé, mas ainda sem 
funcionamento iniciado, não sendo considerado para efeito deste estudo. Cabe mencionar que outras cidades cearenses também possuem campus de instituições públicas estaduais de educação superior.

No caso cearense, a expansão do ensino superior federal pode ser classificada em três processos distintos. Houve a implantação de novos campi relacionados ao projeto de expansão de uma universidade existente, como os campi de Quixadá, Russas e Crateús, pertencentes à UFC. Ocorreu também a implantação de novos campi de uma universidade completamente nova, a Unilab, nos municípios limítrofes de Redenção e Acarape. E deu-se ainda a implantação de campi criados a partir do desmembramento de outros pertencentes à universidade já existente, aos quais foram adicionados outros campi em cidades próximas e passaram a compor uma nova instituição, como aconteceu com a UFCA, cujos campi de Juazeiro do Norte, Barbalha e Crato, anteriormente pertencentes à UFC, foram cedidos à UFCA.

Com o Reuni, foram construídos 11 novos campi de universidades federais no Ceará: 3 da UFC, 3 da Unilab e 5 da UFCA. Isso permitiu uma significativa interiorização do ensino superior federal, já que até 2003 a UFC era a única instituição federal de ensino superior e possuía campi apenas na capital; daí, inclusive, a importância das universidades estaduais. Com aqueles novos campi, as universidades federais passaram a estar presentes em 8 das 14 atuais macrorregiões estaduais, mas apenas em 9 das 33 microrregiões cearenses definidas pelo IBGE. Atualmente, o ensino superior federal está presente em 12 dos 184 municípios cearenses. Do total de 14 campi universitários, 11 estão localizados em cidades com mais de 50 mil habitantes e apenas 4 foram implantados em cidades não metropolitanas.

\section{Ensino técnico e tecnológico e os institutos federais}

Até 2003, o Ceará contava com cinco campi de instituições federais de ensino técnico. Com sede em Fortaleza, o Centro Federal de Educação Tecnológica do Ceará, que havia sido instituído ainda em meados dos anos 1990 a partir da antiga Escola Técnica Federal do Ceará, possuía também unidades em Juazeiro do Norte e Cedro, que, somadas às escolas agrotécnicas de Crato e de Iguatu, constituíam as unidades de ensino técnico federal no Estado. Em 2008, foi criado o Instituto Federal de Educação Ciência e Tecnologia do Ceará (IFCE), integrante da RFEPCT. Esse ano foi o marco temporal do processo de expansão do ensino técnico e tecnológico rumo ao interior do Estado.

Seguindo a estratégia adotada no processo de expansão da RFEPCT de abranger todas as mesorregiões brasileiras com no mínimo um campus, o IFCE elevou a sua capilaridade, acompanhando as três fases de expansão dos IFs. O IFCE nasceu com nove campi: além dos cinco já citados, foram implantados os campi de Quixadá, Maracanaú, Sobral e Limoeiro do Norte. Essa constituiu a fase inicial de implantação e expansão do IFCE para outros municípios. Com a segunda fase, que decorreu até o ano de 2010, foram implementadas mais 12 unidades, e o IFCE passou a contar com 21 campi. A terceira fase da expansão, entre 2014 até 2016, mas que ainda ocorre atualmente, ampliou esse quantitativo para 34 campi. A distribuição atual dos campi do IFCE pode ser vista na Figura 1.

Se, até o começo do século XXI, o ensino técnico federal estava restrito a apenas cinco municípios localizados em apenas duas macrorregiões do Estado, com a criação do IFCE em 2008 e a ampliação do número de campi para nove, essa modalidade de ensino tornou-se presente em sete das oito macrorregiões de então. A partir de 2010, o instituto passou a estar presente em todas as macrorregiões estaduais. Situação semelhante ocorre se observada a distribuição histórica dos campi pelas microrregiões estaduais. Se, até 2007, o ensino técnico federal estava presente em apenas 3 das 33 microrregiões do Estado, com a criação do IFCE em 2008 esse número passou a abranger 20 daquelas unidades de planejamento. Atualmente, o IFCE possui 36 campi localizados em 32 municípios. A localização dos novos campi seguiu, em regra, a diretriz geral de expansão da rede. Do total de 29 novos complexos educacionais implantados a partir de 2008, 20 deles estão em municípios com população superior a 50 mil habitantes. 


\section{A dimensão territorial da expansão educacional}

Conforme já apontado, a recente expansão do ensino federal, por meio de sua democratização e interiorização, apresenta uma dimensão territorial que tem sido menos abordada nos estudos que tratam desse processo. Esta seção busca inserir elementos dessa dimensão, tentando discutir alguns dos aspectos possíveis que permitem relacionar as políticas educacionais e seus efeitos territoriais. Para tanto, recorreu-se a estudos de caso das cidades cearenses não metropolitanas de Quixadá e Crateús, ambas com um novo campus da UFC e do IFCE, com população entre 50 e 100 mil habitantes e, portanto, representativas do universo de municípios diretamente impactados nesse processo de expansão.

Apesar de não trazer aqui todos os efeitos que estão associados à implantação de novos campi de UFs e de IFs, optou-se pela seleção daqueles que puderam ser observados empiricamente, representando, assim, uma leitura inicial de forma a contribuir para o debate sobre esse tema. Dessa forma, serão discutidos como processos relacionados à implantação dos novos complexos educacionais que interferiram na dinâmica e na estrutura intraurbana daquelas cidades: a flexibilização da legislação urbanística, o aumento da demanda por mobilidade urbana, a dinamização do mercado imobiliário local e o incremento do comércio e dos serviços.

\section{A flexibilização da legislação urbanística}

Os novos campi universitários de universidades federais e do instituto federal que foram implantados no Ceará no processo de expansão do ensino federal referidos neste texto apresentam uma lógica que predomina no que se refere à sua localização. Apesar de ocorrerem variações quanto à origem do terreno ou da edificação que passaram a ser ocupados pelos equipamentos educacionais ou quanto ao porte dos campi, predomina a localização periférica nas cidades que receberam tais instituições. Apenas casos pontuais diferem dessa situação, com a grande maioria dos novos campi situando-se distante da malha urbana adensada, por vezes no limite do perímetro urbano ou até mesmo externos a ele.

Essa localização periférica pode ser explicada por algumas razões principais, que têm relação com a origem das terras ocupadas pelas universidades e pelo instituto. Exceção dos campi que passaram a ocupar edificações existentes, já inseridas na malha urbana adensada, os terrenos tinham origem estatal, cedidos por um dos três entes federativos, ou foram doados por particulares, normalmente por membros da elite política ou econômica local. Pela necessidade de lotes de grandes dimensões para viabilizar o funcionamento de um campus e todas as suas instalações acadêmicas, tanto a cessão estatal quanto a doação particular foram feitas a partir da disponibilidade de terrenos periféricos, vazios ou subutilizados. No caso dos terrenos de origem privada, como é o caso da UFC em Crateús, há um nítido interesse na valorização imobiliária do entorno a partir do funcionamento de um campus universitário, conforme será visto adiante.

O resultado é que há uma flexibilização da legislação urbanística associada à implantação desses novos campi. E isso ocorre tanto no sentido de alteração ou desobediência ao zoneamento quanto na ampliação do perímetro urbano legal. Quanto a esse último aspecto, cabe destacar a implantação dos campi da UFC e do IFCE em Quixadá. Localizados em terreno pertencente ao Departamento Nacional de Obras Contra as Secas (DNOCS), vizinho ao Açude do Cedro, os dois campi foram implantados em 2008, com obras de ampliação que se estenderam até recentemente. Pelo zoneamento aprovado com o Plano Diretor de 2000, ainda não revisto, as duas áreas encontravam-se fora do perímetro urbano, sendo consideradas como zona rural. Em 2012, foi aprovada uma nova Lei do Perímetro Urbano, que passou a englobar o setor no qual foram implantados aqueles complexos educacionais, conforme mostrado na Figura 2. 


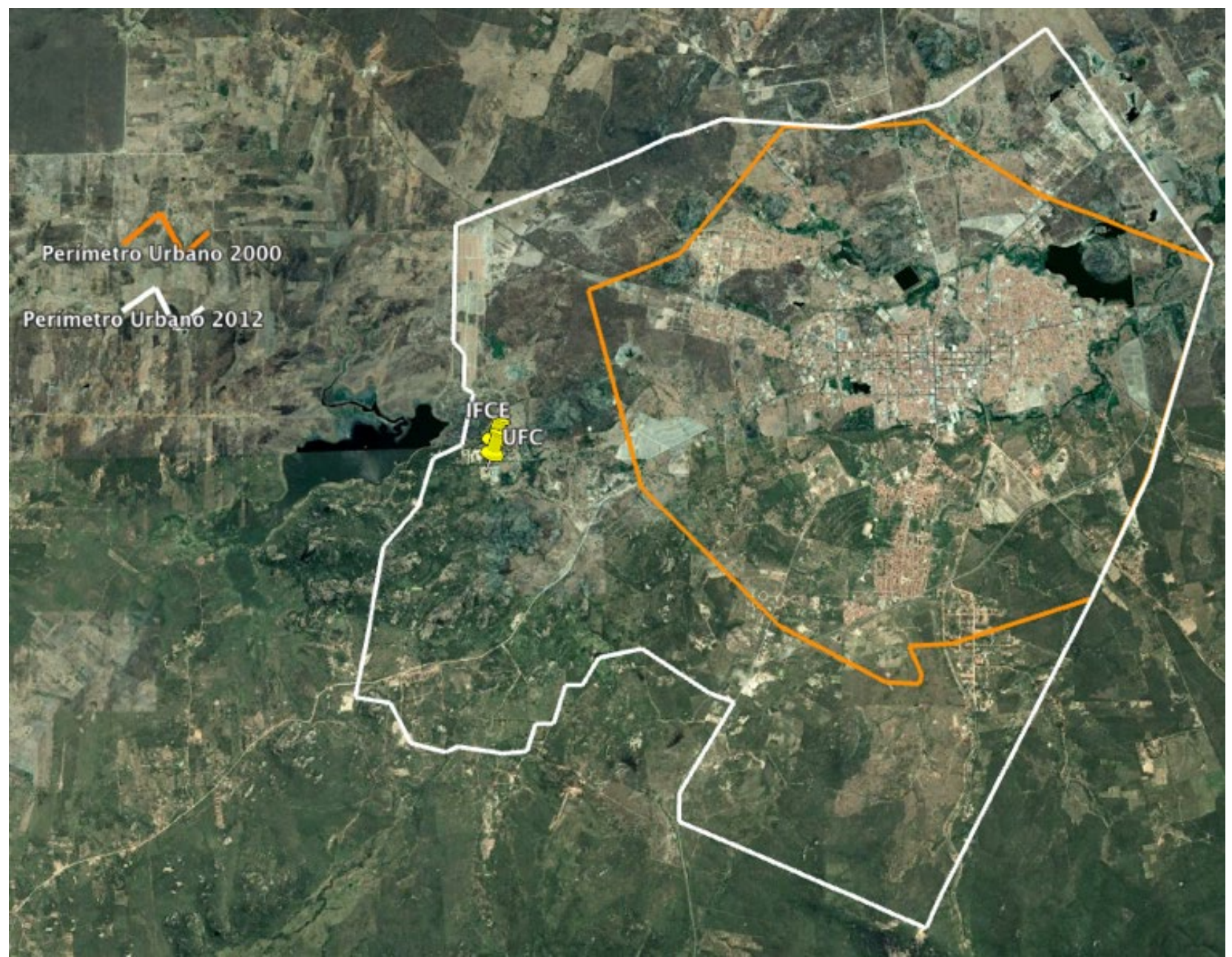

Figura 2 - Perímetro urbano de Quixadá nos anos de 2000 e 2012 e localização dos campi da UFC e do IFCE. Fonte: Elaborado a partir de foto aérea do Google Earth (2019a).

Em Crateús, o que se percebe quanto à implantação dos campi é uma permissividade perante a lei de zoneamento. Nesse documento, elaborado ainda em 2001, a localização de edificações de uso institucional, sendo consideradas enquanto atividades especiais, não está atrelada a nenhuma das zonas delimitadas, devendo ser "[...] objeto de estudos específicos, segundo critérios proporcionais aos impactos que podem causar na estrutura urbana do município" (Ceará, 2001). Conforme classificação da atual lei de zoneamento, o campus do IFCE localiza-se em área urbana, e o campus da UFC, em área de expansão urbana. Ambos não tiveram nenhum estudo específico prévio para avaliar os impactos decorrentes de sua implantação, restando desobediência ao apontado na legislação urbanística.

\section{Aumento da demanda por mobilidade urbana}

Exatamente pela localização periférica dos novos campi de universidades e institutos federais, surgiu uma maior demanda por mobilidade urbana associada a um novo público até então ausente nesses municípios. Em Quixadá, por exemplo, dos 2.029 alunos matriculados na UFC e no IFCE, 82\% moravam na própria cidade ou em municípios fora da microrregião, o que indica um grupo de usuários que demandava alguma forma de mobilidade para se deslocar diariamente até os campi. Tais instalações, que se tornaram polos geradores de tráfego, encontram-se distantes da malha urbana adensada. No caso de Quixadá, os campi da UFC e do IFCE, praticamente vizinhos, distam 5,2 km da igreja matriz localizada no centro da cidade, em trecho acessível apenas por rodovia. Em Crateús, o campus do IFCE é mais central, 
distante 2,5 km da igreja matriz daquela cidade. Já o campus da UFC fica em trecho periférico e distante $3,8 \mathrm{~km}$ da região central, em trecho acessível apenas por rodovia.

Somadas a essas distâncias, o problema da mobilidade é agravado pelas condições de acessibilidade e da inexistência de sistema público de transporte. Assim, servidores e alunos, além de outros usuários eventuais, passavam a utilizar as opções disponíveis nessas cidades para poder se locomover até a UFC e o IFCE. Táxis, mototáxis, bicicletas, caronas ou deslocamentos a pé eram algumas das formas encontradas para realizar a mobilidade até os campi. Cabe destacar que o transporte de alunos, entre a área central e os campi, estava previsto em convênio entre as prefeituras e os municípios, mas isso não funcionava de maneira adequada, havendo recorrentes manifestações estudantis para garantia desse serviço e ainda pressão das administrações municipais em romper tal compromisso. Restava como opção a oferta das próprias instituições de ensino de seus veículos para minimizar os efeitos do problema de mobilidade.

\section{Incremento do comércio e dos serviços}

Outro processo que está associado à interiorização do ensino superior é o incremento do comércio e dos serviços locais, que passam a ser demandados por um novo público, constituído por alunos das diversas modalidades de cursos oferecidos e por servidores das instituições, e classificado em três grupos principais. Um primeiro grupo é formado por aqueles que já são moradores da cidade, usuários do comércio e dos serviços locais, mas que, por causa das atividades associadas ao campus que frequentam, passam a gerar novas demandas. Um segundo é composto daqueles que são oriundos de outras cidades, mas que passam a morar permanentemente na cidade - aqui se trata, sobretudo, de servidores da UFC e do IFCE. Por último, há um terceiro grupo, formado tanto por servidores quanto por alunos, que também são de outros municípios, mas que residem sazonalmente, passando a semana ou parte dela, ou mesmo aqueles que, moradores de cidades próximas, fazem um percurso diário até o local onde o campus está instalado. Por conta disso, passam a movimentar o comércio e o serviços locais existentes, mas também a demandar novos serviços.

A dinamização da economia local também ocorre desde antes do funcionamento pleno dos novos campi. As diversas obras para reforma e construção de blocos didáticos e administrativos e outros espaços acadêmicos demandavam insumos buscados, ao menos parcialmente, no mercado local. Ademais, a própria incorporação de mão de obra temporária para realização das construções também injetava recursos que impactavam a economia local. Cabe acrescentar ainda a folha de pagamento dos servidores das instituições federais de ensino, profissionais cuja renda era bastante superior à renda mensal média dos moradores locais. Ainda que esses servidores, em sua maioria, não fossem residentes locais, eles passavam boa parte da semana na cidade, o que gerava, inclusive, uma demanda por novos comércios e serviços. Há de considerar ainda os recursos institucionais destinados à assistência estudantil que iam conformar uma renda complementar a uma parcela dos estudantes.

\section{Dinamização do mercado imobiliário local}

Em associação à dinamização econômica, tem-se a dinamização do mercado imobiliário local a partir de dois principais processos: a construção de edificações para locação e a implantação de loteamentos e condomínios residenciais. Quanto ao incremento do mercado de locação residencial, isso está associado diretamente ao público que frequenta as cidades a partir da instalação dos novos campi. Excluindo aqueles grupos de servidores e alunos que realizavam movimentos pendulares diários e aqueles que já residiam na própria cidade, o restante de usuários permanentes demandava locais de moradia. Passou a surgir uma maior procura por casas e apartamentos para locação, sobretudo nas áreas centrais, que também presenciavam o aumento da demanda em hotéis e pousadas. 
Percebendo esse aumento da demanda por imóveis para locação, empresários locais, donos de pequenos capitais e mesmo moradores que possuíam imóvel próprio passaram a investir na construção de imóveis verticalizados de até quatro pavimentos, composto de pequenos e médios apartamentos, de no máximo dois quartos, voltados para estudantes que iam constituir as chamadas repúblicas. Na paisagem urbana de Quixadá e de Crateús, já é bastante presente essa tipologia de edificação, conforme visto na Figura 3. Surgiram, inclusive, outros negócios associados ao incremento desse mercado, como as imobiliárias. Ao mesmo tempo que alavancou o mercado imobiliário, a chegada desse novo público acentuou a procura por moradias e fez com que os preços dos aluguéis superassem os índices inflacionários.

Ainda que de maneira menos significativa quanto os prédios de apartamentos, foi ampliada a procura por terrenos. Em associação à elevação do crédito imobiliário residencial no mesmo período em que se deu a expansão do ensino federal, foi observada a implantação de novos loteamentos, conforme mostra a Figura 4. Parte dos lotes foram comercializados para professores e técnicos da UFC e do IFCE, tanto para moradia quanto para investimento. Mas há outra conexão importante entre o mercado imobiliário e a instalação da universidade e do instituto. 0 próprio campus passou a funcionar como vetor de valorização imobiliária das terras no seu entorno. As localizações daqueles empreendimentos em áreas distantes da malha urbana efetivamente adensada, em certos casos transformando áreas rurais em urbanas, contribuíram para o processo definido como urbanização dispersa (Reis, 2006) ou urbanização em saltos (Campos, 1999). Caracteriza tal processo a existência de grandes glebas desocupadas situadas entre o centro concentrador da malha e infraestrutura urbana e da riqueza e a periferia. Decorre uma retenção especulativa de terras que beneficia os proprietários imobiliários ao se apropriarem dos investimentos públicos que passam a se direcionar aos setores ocupados pelos novos complexos educacionais.
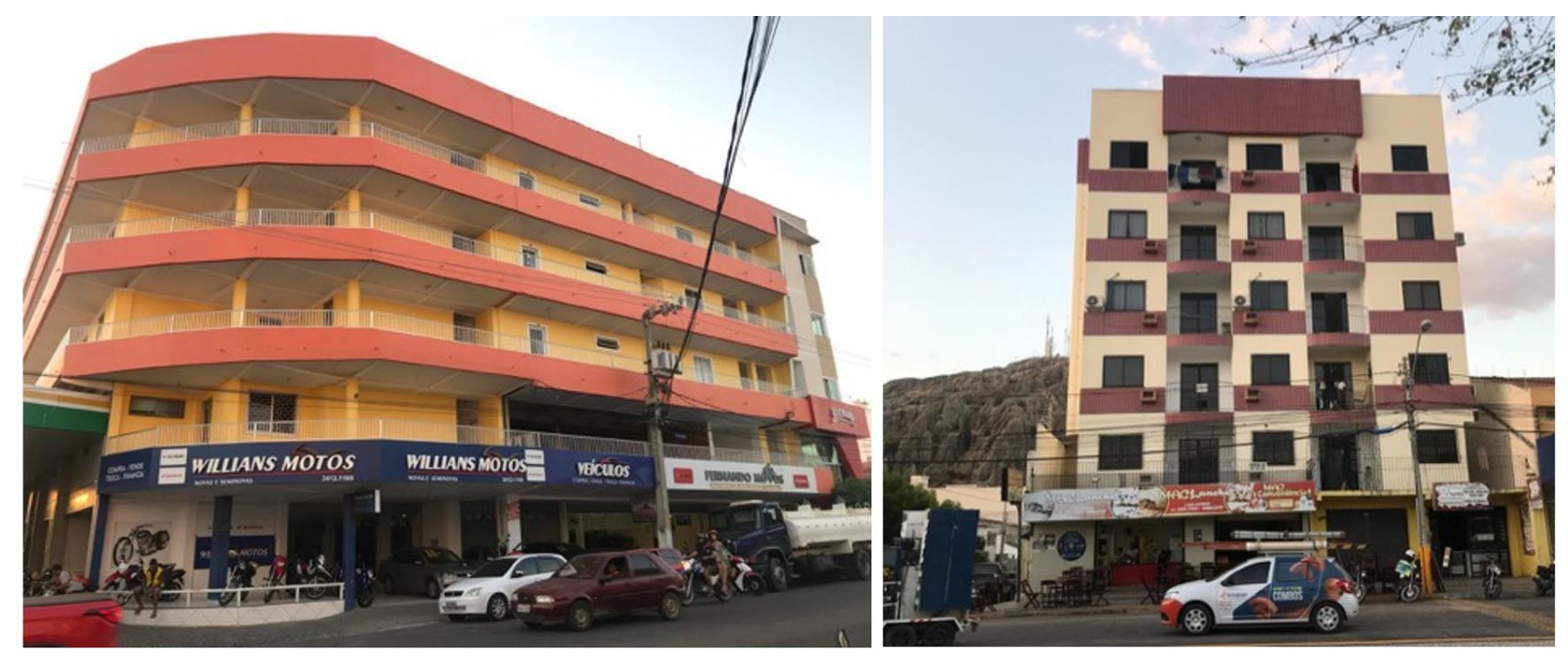

Figura 3 - Imóveis verticalizados para locação e ocupados, principalmente, por estudantes em Quixadá. Fonte: Acervo pessoal. 


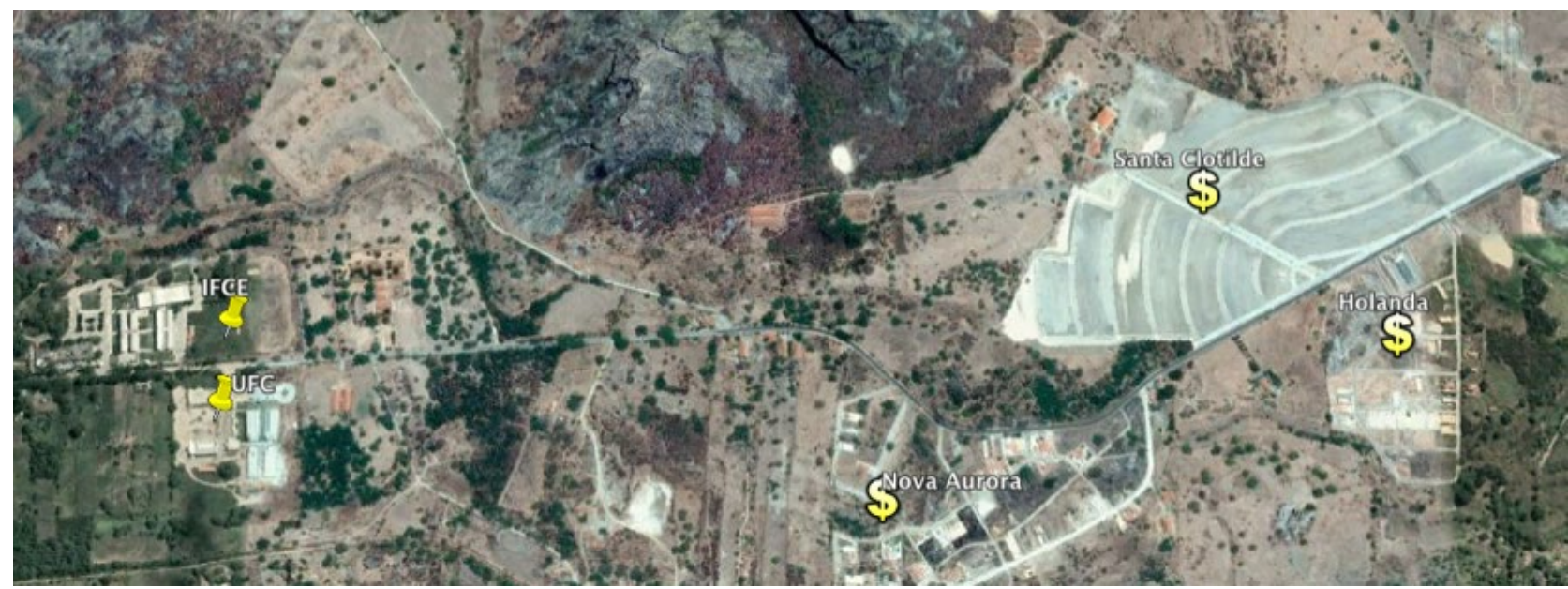

Figura 4 - Empreendimentos imobiliários no entorno dos campi da UFC e do IFCE em Quixadá. Fonte: Elaborada a partir de foto aérea do Google Earth (2019b).

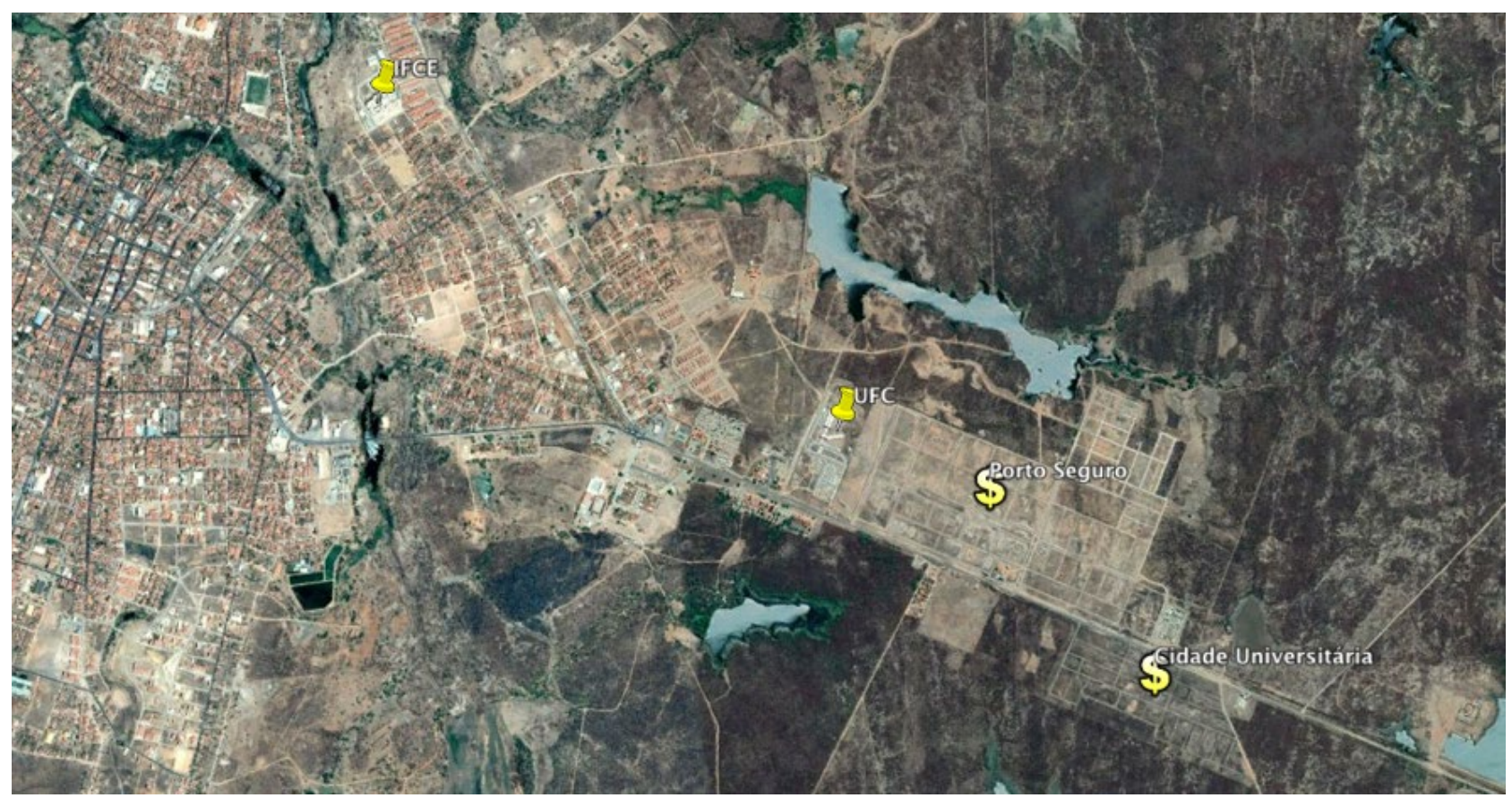

Figura 5 - Empreendimentos imobiliários no entorno do campus da UFC em Crateús. Fonte: Elaborada a partir de foto aérea do Google Earth (2019c).

Em Quixadá, os dois campi localizam-se em setor que já possuía um antigo empreendimento imobiliário, com poucas edificações construídas, e que passou a ter maior valorização a partir da instalação dos complexos educacionais. Posteriormente, surgiram mais dois grandes loteamentos voltados para classes de maior renda, constituindo vetor de expansão urbana rumo à área em que estão localizados o IFCE e a UFC. No caso de Crateús, o campus da UFC está localizado em trecho de antigo loteamento residencial, conforme indicado na Figura 5. Uma gleba desse loteamento foi doada à prefeitura que, posteriormente, cedeu à universidade. Tal movimento demonstra nitidamente o interesse do proprietário em obter ganhos imobiliários com a presença da universidade no entorno do seu empreendimento. 


\section{Considerações finais}

Não se pretendeu realizar uma discussão sobre o mérito da política educacional que expandiu o ensino por meio das UFs e dos IFs, nem tampouco avaliar seus impactos. Buscou-se contribuir para o debate sobre essa recente expansão do ensino federal, inserindo o componente territorial nas análises que têm sido feitas sobre tal processo, na medida em que se constata uma relativa carência de estudos acerca dos efeitos que a recente expansão do ensino federal causou nas cidades, e mesmo nas regiões, alvos dessas ações. Contudo, cabe apontar que a dimensão educacional não está isolada do aspecto territorial e que algumas críticas já feitas sobre aquele primeiro aspecto servem para caracterizar alguns dos pontos levantados sobre o segundo. Por exemplo, algumas questões aqui discutidas estão associadas diretamente ao desenho dessa política educacional, implementada em uma necessária, mas rápida e desordenada, expansão. Sem também avançar nessa discussão, cabe destacar o novo papel que as universidades e os institutos federais passaram a apresentar em relação à economia e à sociedade brasileira, sobretudo por causa do processo recente de desconcentração e interiorização do ensino federal.

Dessa forma, para além do significativo impacto no acesso ao ensino, a implantação desses complexos educacionais está associada a alterações no espaço intraurbano. Conforme visto, ocorre um relativo aumento populacional, ainda que parcialmente sazonal, resultado da atração de alunos e servidores dessas instituições de ensino, que passam a movimentar o setor de comércio e serviços com demandas específicas voltadas para as atividades institucionais ou individuais. Tal população incrementa também o mercado imobiliário local por meio da procura por terrenos em loteamentos ou por imóveis residenciais para locação. Observa-se ainda o aumento da demanda por mobilidade, seja urbana, para o acesso ao campus ou outras atividades cotidianas, seja regional, na medida em que os campi passam a atender a estudantes de municípios próximos. Há ainda, por parte desse novo público, impacto nas redes de infraestrutura e nos serviços urbanos. Ademais, decorre uma flexibilização da legislação urbanística associada à localização periférica dos campi.

Ao apresentar e discutir aspectos sobre a dimensão territorial do processo de expansão do ensino federal para áreas não metropolitanas, argumenta-se que a implantação desses novos campi está associada à alteração da dinâmica e da estrutura intraurbana dessas cidades. Os estudos de caso trabalhados - os campi da Universidade Federal do Ceará e do Instituto Federal do Ceará implantados nas cidades de Crateús e Quixadá - permitiram mostrar esse processo. Tais cidades, conforme visto, são representativas da interiorização do ensino federal em cidades cearenses não metropolitanas, por conta de possuírem porte característico dos municípios que passaram a abrigar novos campi universitários e ainda por possuírem tanto um campus de uma universidade federal quanto um campus de um instituto federal. Essa condição permite uma certa aproximação entre a realidade dessas duas cidades, ao mesmo tempo que as tornam emblemáticas do processo que se pretendeu discutir. Caberia aprofundar os estudos e analisar outras cidades, de forma a melhor entender os impactos territoriais das políticas educacionais.

\section{Referências}

Associação Nacional dos Dirigentes das Instituições Federais de Ensino Superior - Andifes. (2011). Perfil socioeconômico e cultural dos estudantes de graduação das universidades federais brasileiras. Brasília: Fórum Nacional de Pró-Reitores de Assuntos Comunitários e Estudantis.

Brasil. (2001, 9 de janeiro). Lei Federal n. 10.172, de 9 de janeiro de 2001. Aprova o Plano Nacional de Educação e dá outras providências. Brasília: Diário Oficial da União. Recuperado em 6 de abril de 2019, de http://www.planalto.gov.br/ccivil_03/LEIS/LEIS_2001/L10172.htm 
Brasil. (2007a, 24 de abril). Decreto n. 6.096, de 24 de abril de 2007. Institui o Programa de Apoio a Planos de Reestruturação e Expansão das Universidades Federais - REUNI. Brasília: Diário Oficial da União. Recuperado em 6 de abril de 2019, de http://www.planalto.gov.br/ccivil_03/_Ato2007-2010/2007/Decreto/D6096.htm

Brasil. Ministério da Educação. (2007b). Relatório de avaliação do plano de expansão da rede federal de educação tecnológica. Brasília: Secretaria de Educação Profissional e Tecnológica.

Brasil. (2008, 29 de dezembro). Lei Federal n. 11.892, de 29 de dezembro de 2008. Institui a Rede Federal de Educação Profissional, Científica e Tecnológica, cria os Institutos Federais de Educação, Ciência e Tecnologia, e dá outras providências. Brasília: Diário Oficial da União. Recuperado em 6 de abril de 2019, de http://www.planalto.gov.br/ccivil_03/_Ato2007-2010/2008/Lei/L11892.htm

Brasil. Ministério da Educação. (2009). Centenário da Rede Federal de Educação Profissional e Tecnológica. Brasília: Secretaria de Educação Profissional e Tecnológica. Recuperado em 6 de abril de 2019, de http://portal.mec.gov.br/setec/arquivos/centenario/historico_educacao_profissional.pdf

Brasil. Ministério da Educação. (2011). Prestação de contas ordinária anual: relatório de gestão 2010. Brasília: Secretaria de Educação Profissional e Tecnológica. Recuperado em 6 de abril de 2019, de http://portal.mec.gov.br/index.php?option=com_docman\&view=download\&alias=8006-relatorio-gestao-2010setec-versaofinal-cgu-pdf\&category_slug=maio-2011pdf\&Item id=30192

Brasil. Ministério da Educação. (2012). Análise sobre a expansão das universidades federais 2003 a 2012. Brasília: Secretaria do Ensino Superior. Recuperado em 6 de abril de 2019, de http://portal.mec.gov.br/index.php?option=com_docman\&view=download\&alias=12386-analise-expansaouniversidade-federais-2003-2012-pdf\&Itemid $=30192$

Brasil. Ministério da Educação. (2014). A democratização e expansão da educação superior no país 2003-2014. Brasília: Secretaria do Ensino Superior. Recuperado em 6 de abril de 2019, de http://portal.mec.gov.br/index.php?option=com_docman\&view=download\&alias=16762-balanco-social-sesu2003-2014\&Itemid=30192

Campos, C. M., Fo. (1999). Cidades brasileiras: seu controle ou o caos. São Paulo: Nobel.

Canziani, A., Martins, R. C. R., \& Santos, A. F. (2018). Financiamento da educação superior no Brasil: impasses e perspectivas (Série Estudos Estratégicos, No. 11). Brasília: Câmara dos Deputados, Edições Câmara.

Ceará. (2001, 28 de junho). Lei Municipal no 449, de 28 de junho de 2001. Dispõe sobre o parcelamento, uso e ocupação do solo do Município de Crateús e dá outras providências. Crateús: Diário Oficial do Estado.

Corbucci, P. R. (2014). Evolução do acesso de jovens à educação superior no Brasil (Texto para Discussão, 1950). Brasília: IPEA.

Google Earth. (2019a). Perímetro urbano de Quixadá, 459'20"S, 3902'46"W, elevação 10665m. Recuperado em 6 de abril de 2019, de https://earth.google.com/web

Google Earth. (2019b). Bairro Cedro e entorno em Quixadá, 458'53"S, 3903'03"W, elevação 2961m. Recuperado em 6 de abril de 2019, de https://earth.google.com/web

Google Earth. (2019c). Bairro Venâncios e entorno em Crateús, 511'35"S, 40³8'18"W, elevação 3804m. Recuperado em 6 de abril de 2019, de https://earth.google.com/web

Instituto Brasileiro de Geografia e Estatística - IBGE. (2000). Censo demográfico 2000: dados da amostra. Rio de Janeiro: IBGE. Recuperado em 6 de abril de 2019, de http://censo2000.ibge.gov.br

Instituto Brasileiro de Geografia e Estatística - IBGE. (2010). Censo demográfico 2010: dados da amostra. Rio de Janeiro: IBGE. Recuperado em 6 de abril de 2019, de http://censo2010.ibge.gov.br

Instituto Nacional de Estudos e Pesquisas Educacionais Anísio Teixeira - INEP. (2014a). Censo da educação superior 2014: microdados para download. Brasília: INEP. Recuperado em 6 de abril de 2019, de http://portal.inep.gov.br/microdados 
Instituto Nacional de Estudos e Pesquisas Educacionais Anísio Teixeira - INEP. (2014b). Sinopses estatísticas da educação superior - 2014. Brasília: INEP. Recuperado em 6 de abril de 2019, de http://inep.gov.br/sinopsesestatisticas-da-educacao-superior

Lima, K. (2011). O Banco Mundial e a educação superior brasileira na primeira década do novo século. Revista Katálysis, 14(1), 86-94. http://dx.doi.org/10.1590/S1414-49802011000100010.

Mota, A. (2016). Os limites e as possibilidades do Programa Reuni: um estudo de caso da experiência da UFT (Dissertação de mestrado). Programa de Pós-graduação em Gestão de Políticas Públicas, Universidade Federal do Tocantins, Palmas.

Organisation for Economic Cooperation and Development - OCDE. (2012). Education at a Glance 2012: OECD indicators. Paris: OECD Publishing. Recuperado em 6 de abril de 2019, de https://bit.ly/20j7SxP

Pacheco, E. (2010). Os Institutos Federais: uma revolução na educação profissional e tecnológica. Brasília: Ministério da Educação, Secretaria de Educação Profissional e Tecnológica.

Pacheco, E. M., Pereira, L. A. C., \& Domingos, M., So. (2010). Institutos Federais de Educação, Ciência e Tecnologia: limites e possibilidades. Linhas Críticas, 16(30), 71-88. http://dx.doi.org/10.26512/lc.v16i30.3568.

Pereira, T. L., \& Brito, S. H. A. (2018). A expansão da educação superior privada no Brasil por meio do FIES. EccoSRevista Científica, 47(47), 337-354. http://dx.doi.org/10.5585/eccos.n47.7895.

Reis, N. G. (2006). Notas sobre urbanização dispersa e novas formas de tecido urbano. São Paulo: Via das Artes.

Santos, R. S. (2015). A interiorização da educação superior no Estado do Ceará. Revista Gestão Universitária, 4(2). Recuperado em 6 de abril de 2019, de http://gestaouniversitaria.com.br/artigos/a-interiorizacao-da-educacaosuperior-no-estado-do-ceara

Tribunal de Contas da União - TCU. (2012). Relatório de auditoria TC 026.062/2011-9. Brasília: TCU. Recuperado em 6 de abril de 2019, de https://bit.ly/20UmFgb

Editor: Rodrigo Firmino

Recebido: Abr. 06, 2019

Aprovado: Nov. 17, 2019 